UDK 632.52

Naučni rad-Scientific paper

\title{
Prisustvo otrovnih drvenastih vrsta na zelenoj površini Vrtića „Suncokreti“" u naselju višnjička banja, Beograd
}

\author{
Slađana Vićentić, Nenad Stavretović, Marijana Novaković \\ Šumarski fakultet, Kneza Višeslava 1, Beograd \\ sladjanavicentic@yahoo.com
}

REZIME

Otrovne drvenaste i žbunaste vrste nisu poželjne na zelenim površinama školskih a naročito predškolskih ustanova. Međutim, brojne otrovne drvenaste i žbunaste vrste se nalaze na pomenutim površinama, što predstavlja ozbiljnu pretnju po zdravlje dece. Cilj rada je utvrđivanje prisutnosti otrovnih drvenastih i žbunastih vrsta na zelenoj površini obdaništa „Suncokreti“ u prigradskom naselju Višnjička banja u Beogradu, kao i davanje predloga za negu i održavanje objekata ovog tipa. Rezultati su pokazali prisustvo 11 otrovnih vrsta. Po najvećem stepenu otrovnosti izdvajaju se vrste Thuja orientalis L., Laburnum anagyroides Med. $i$ Taxus baccata L. koje, u slučaju dospeća u ljudski organizam, izazivaju teška trovanja koja mogu imati fatalan ishod.

Ključne reči: otrovne vrste, obdaništa, pejzažna arhitektura, hortikultura 


\section{UVOD}

$\mathrm{Na}$ zelenim površinama predškolskih i školskih ustanova mogu se naći različite drvenaste vrste među kojima ima invazivnih, alergenih i otrovnih (Vićentić i sar. 2015). Otrovne drvenaste vrste razlikuju se po stepenu svoje otrovnosti. U slučaju dospeća u ljudski organizam neke otrovne biljke mogu izazvati manje, neke veće poremećaje, a pojedine mogu dovesti i do smrtnog ishoda.

Otrovne biljke se mogu generalno podeliti u tri grupe. U prvu grupu otrovnih biljaka spadaju izrazito toksične biljke koje, u slučaju da dospeju u ljudski organizam čak i u manjim količinama, izazivaju ozbiljna trovanja. Ove biljke sadrže veoma otrovne materije poput alkaloida, glikozida, toksalbumina (Ivanić i sar. 1996).U slučaju da se pomoć ne ukaže na vreme, može doći do teških poremećaja, pa i do fatalnog završetka (Frohne, Pfänder, 1997; Ivanić i sar. 1996).

Drugu grupu, u koju spada daleko veći broj otrovnih biljaka, čine vrste koje takođe sadrže sastojke jakog dejstva, hemijski sličnog sastava kao iz prethodne grupe. Ipak sadržaj otrovnih sastojaka je manje toksičan nego kod biljaka iz prve grupe. U slučaju dospeća ovih biljaka u ljudki organizam, dolazi do trovanja, ali bez fatalnog ishoda. Samo u određenim slučajevima, pod određenim uslovima, ove biljke mogu izazvati ozbiljnije trovanje (Frohne, Pfänder, 1997; Ivanić i sar. 1996).

U treću grupu spadaju biljke koje se smatraju otrovnim, dovode do izvesnih simptoma trovanja, međutim one nemaju tačno definisane otrovne sastojke, kao prethodne dve grupe. Nisu zabeleženi slučajevi dokazanih i potvrđenih teških trovanja ovim bilikama (Frohne, Pfänder, 1997; Ivanić i sar. 1996).

Otrovna jedinjenja iz biljaka mogu na različite načine dospeti do organizma čoveka tj. dece. Pojedine vrste, odnosno njihovi delovi (list, plod, seme, pa čak i kora kod nekih vrsta) mogu biti izuzetno otrovni ako se progutaju. Kod nekih otrovnih vrsta sam kontakt sa biljkom može dovesti do trovanja, kada se preko kože izlučuje otrov u organizam, pri čemu se javljaju različite promene na koži. Takve biljke se nazivaju kontakt-alergene biljke (Ivanić i sar. 1996).

Neke od biljaka koje su u ovom radu navedene kao otrovne mogu imati i lekovita svojstva, a pojedine i jestive delove. Da li je određena biljka otrov ili lek, zavisi od načina upotrebe, količine otrovnih sastojaka u biljci, kao i od toga koji deo biljke i u kom delu vegetacionog perioda se koristi, s obzirom da pojedine biljne vrste menjaju količinu otrovnih materija u svojim organima u toku vegetacionog perioda.

Otrovne drvenaste i žbunaste vrste nisu poželjne na zelenim površinama školskih a naročito predškolskih ustanova. Uprkos tome brojne otrovne drvenaste i žbunaste vrste se mogu naći u njima, što može predstavljati ozbiljnu pretnju po zdravlje dece. Cilj rada je utvrđivanje prisutnosti otrovnih drvenastih i žbunastih vrsta na zelenoj površini obdaništa „Suncokreti“ u prigradskom naselju Višnjička banja u Beogradu. 


\section{MATERIJAL I METODE}

Istraživanja su vršena na zelenoj površini obdaništa „Suncokreti“ u prigradskom naselju Višnjička banja u Beogradu. Determinacija drvenastih i žbunastih vrsta određena je prema Vukićević (1996), Ocokoljić i Ninić-Todorović (2003), Šilić (1990), Cvjetićanin i Perović (2010). Otrovne drvenaste vrste su izdvojene prema Grlić (1984), Frohne, Pfänder (1997), Ivanić i sar. (1996). Stepen otrovnosti za vrste utvrđen je prema Ivanić i sar., (1996) i Frohne, Pfänder (1997). U odnosu na to da li izazivaju blaža, teža ili vrlo teška smrtonosna trovanja u slučaju unosa u organizam, konstatovane otrovne vrste podeljene su na uslovno toksične, toksične, veoma toksične, i vrste koje izazivaju veoma teška, fatalna trovanja.

U zavisnosti od visine drveta, grana koje mogu biti savijene, niže postavljene, ili kretati od zemlje kao kod četinara, otrovni delovi poput cveta, ploda, semena mogu biti manje ili više dostupni deci, pa je iz tog razloga izvršen premer elemenata rasta stabala. Visina stabla (h) određena je Blume-Leis-ovim visinomerom prema Banković i Pantić (2006). Prsni prečnik stabla (d) meren je milimetarskom prečnicom unakrsno u dva pravca pod pravim uglom na prsnoj visini od 1,30m (Banković i Pantić, 2006). Visina debla (b) određena je metrom ili Blume-Leis-ovim visinomerom. Premer širine krošnje (ld) vršen je pantljikom u dva pravca pod pravim uglom. Kod vrsta koje su zastupljene sa više primeraka na istraživanoj površini izračunate su prosečne vrednosti merenih elemenata rasta stabala.

\section{REZULTATI}

U dvorištu vrtića „Suncokreti“ zabeleženo je 26 drvenastih vrsta sa 227 stabala. Prisutno je i pet vrsta žbunastog habitusa, kao i dve povijuše. Od ukupno 26 evidentiranih drvenastih vrsta na ovoj površini, 9 vrsta poseduje alergene karakteristike polena, a jedna vrsta invazivne karakteristike. Od ukupno 26 drvenastih vrsta 6 spada u one čiji su pojedini delovi ili cela biljka-otrovne (Thuja orientalis L., Laburnum anagyroides Med., Robinia pseudoacacia L., Rhus typhina L., Quercus virgilliana Ten., Aesculus hippocastanum L.). Od pet drvenastih vrsta žbunastog habitusa, 3 vrste spadaju u otrovne (Taxus baccata L., Prunus laurocerasus L., Ligustrum vulgare L.). Uočene su dve otrovne povijuše (Hedera helix L., Clematis vitalba L.). Ukupno je prisutno 11 otrovnih vrsta.

Vrsta T. orientalis zastupljena je sa 1 primerkom na ovoj površini, čija je visina $6,5 \mathrm{~m}$, prsni prečnik 7,6 cm, a širina krošnje u proseku 2,4 m. Grane kreću od zemlje. Po stepenu otrovnosti (Tabela 1) T. orientalis spada u veoma toksične biljke, koje izazivaju veoma teška trovanja koja se mogu završiti i fatalno. Svi delovi ove biljke su 
otrovni, a naročito vrhovi grančica koji sadrže smone žlezde.

Uočeno je 3 stabla vrste L. anagyroides. Prosečna visina stabala je 3,6 m, prsni prečnik $6,2 \mathrm{~cm}$, dok je prosečna širina krošnje 2,0 m. Prosečna visina debla iznosi 1,5 m. Cela biljka je otrovna. L. anagyroides spada u veoma toksične biljke (Tabela 1). Kod ove vrste decu posebno mogu privući cvetovi žute boje koji podsećaju na cvetove bagrema, i semenke.

Konstatovano je 38 stabala vrste $R$. pseudoacacia na istraživanoj površini, a mereni elementi rasta su imali sledeće srednje vrednosti. Prosečna visina iznosi 11,9 m, prsni prečnik $20,5 \mathrm{~cm}$, visina debla $2,1 \mathrm{~m}$, a prosečna širina krošnje $5,8 \mathrm{~m}$. Svi delovi biljke, osim cvetova čiji nektar je jestiv, su otrovni (kora, mahuna, seme). Po stepenu otrovnosti $R$. pseudoacacia spada u toksične vrste (Tabela 1), retka su teška trovanja. Ovo je jedina invazivna drvenasta vrsta na ovoj površini.

Tabela 1. Otrovne vrste na zelenoj površini vrtića „Suncokreti“ u Višnjičkoj banji, Beograd

\begin{tabular}{|c|c|c|c|c|}
\hline Vrsta & $\begin{array}{l}\text { Broj } \\
\text { stabala }\end{array}$ & Otrovni delovi & Otrovna materija & $\begin{array}{c}\text { Stepen } \\
\text { otrovnosti }\end{array}$ \\
\hline Thuja orientalis & 1 & $\begin{array}{c}\text { Cela bilikaa, } \\
\text { vrhovi grančica }\end{array}$ & Etarsko ulje, smola & $* * * !$ \\
\hline Laburnum anagyroides & 3 & $\begin{array}{l}\text { Cela biljka, } \\
\text { cvetovi, seme }\end{array}$ & Alkaloidni citizin i dr. & $* * *$ \\
\hline Robinia pseudoacacia & 38 & $\begin{array}{l}\text { Cela biljka } \\
\text { osim cvetova }\end{array}$ & Toksalbumin, robin & $* *$ \\
\hline Rhus typhina & 1 & Cvast, list, kora & $\begin{array}{l}\text { Mlečni sok, kiseline } \\
\text { visok sadržaj tanina }\end{array}$ & * \\
\hline Quercus virgilliana & 2 & $\begin{array}{c}\text { Visok sadržaj tanina } \\
\text { u celoj biljci }\end{array}$ & Visok sadržaj tanina & * \\
\hline Aesculus hippocastanum & 3 & Seme & Saponin escin & $* *$ \\
\hline Taxus baccata & žbun & $\begin{array}{l}\text { Cela biljka, } \\
\text { osim arilusa }\end{array}$ & Taksin-smesa alkaloida & $* * * !$ \\
\hline Prunus laurocerasus & žbun & $\begin{array}{l}\text { Cela biljka osim } \\
\text { mesnatogdela ploda }\end{array}$ & Cijanogeni glikozidi & $*$ \\
\hline Ligustrum vulgare & žbun & Plodovi & $\begin{array}{c}\text { Saponozidi, glikozidi } \\
\text { i seko-iridoid }\end{array}$ & $* * *$ \\
\hline Hedera helix & povijuša & Cela biljka, plodovi & hederasaponini & $* *$ \\
\hline Clematis vitalba & povijuša & Cela biljka & protoanemnin & $*$ \\
\hline
\end{tabular}

Legenda: ${ }^{*}$-uslovno toksičan; ${ }^{* *}$-toksičan; ${ }^{* * *}$-veoma toksičan!; -trovanja veoma teška, fatalna

Vrsta R. typhina prisutna je sa 1 stablom na istraživanoj površini. Visina biljke iznosi 3,5 m, a prsni prečnik 10,9 cm. Visina debla iznosi $1,9 \mathrm{~m}$, dok je prosečna širina krošnje 4,5 m. Štetni mogu biti cvast, list i kora. Ova vrsta spada po stepenu otrovnosti u uslovno toksične biljke (Tabela 1). 
Uočeno je 2 stabla vrste Q. virgilliana. Prosečna visina stabala je $13,5 \mathrm{~m}$, prsni prečnik 41,2 cm, visina debla iznosi 1,5 m, a širina krošnje 9,2 m. Vrste iz roda Quercus imaju visok sadržaj tanina, i mogu biti uslovno toksične (Tabela 1).

Zabeleženo je 3 primerka vrste $A$. hippocastanum na istraživanoj površini. Prosek merenih elemenata rasta je sledeći: visina stabala iznosi 7,2 m, prsni prečnik $12,7 \mathrm{~cm}$, visina debla i širina krošnje iznose $1,5 \mathrm{~m}$, odnosno 1,9 m. Seme ove vrste sadrži saponin escin.

$\mathrm{Na}$ istraživanoj površini konstatovane su tri otrovne žbunaste vrste T. baccata, P. laurocerasus, L. vulgare. Uočeno je dva žbuna većih dimenzija vrste T. baccata. Cela biljka je otrovna, četine, seme, sve osim mesnatog dela-omotača semena (arilusa) koji je jestiv. Po stepenu otrovnosti T. baccata spada u vrste koje, u slučaju dospeća u ljudski organizam, mogu izazvati veoma teška trovanja sa fatalnim ishodom (Tabela 1). Vrsta T.baccata nalazi se na listi zaštićenih vrsta.

Vrsta P. laurocerasus prisutna je sa dva žbuna na istraživanoj površini. Cela biljka je otrovna (lišće, koštice), mesnati deo ploda nije otrovan. Po stepenu otrovnosti $P$. laurocerasus spada u uslovno toksične biljke (Tabela 1 ), trovanja su retka.

Vrsta L. vulgare prisutna je na jednom manjem delu istraživane površine kao „živa ograda“. Otrovni su plodovi ove vrste, a po stepenu otrovnosti ova vrsta spada u vrlo toksične biljke, iako se trovanja retko dešavaju (Tabela 1).

Povijuša $H$. helix prisutna je pored ograde i na jednoj manjoj površini na istraživanom lokalitetu. Cela biljka je otrovna (listovi i plodovi).U odnosu na stepen otrovnosti (Tabela 1), ova biljka spada u toksične, a može imati i kontakt alergeno dejstvo.

Povijuša $C$. vitalba takođe je prisutna na jednom manjem delu istraživane površine pored ograde. Cela biljka je otrovna, a po stepenu otrovnosti spada u uslovno otrovne vrste, sa mogućim kontakt alergenim delovanjem.

\section{DISKUSIJA}

Do trovanja otrovnim biljem najčešće dolazi nepažnjom, slučajno, ili zamenom neotrovnih i otrovnih biljaka (Lawrence, 1997). Trovanja se najčešće dešavaju u pozno leto kada počinje sazrevanje plodova kod većine biljaka. U Švajcarskoj je zabeležen slučaj trovanja 16-oro dece semenom zanoveti (L. anagyroides) posađene oko ograde vrtića (Ivanić i sar. 1996). Prema podacima toksikološkog centra Švajcarske iz 1978.godine, najveći broj zabeleženih trovanja prouzrokovalo je konzumiranje plodova pasjeg grožđa (Lonicera caprifolia L.) (ukupno 56), i u svim slučajevima radilo se o deci. Zatim slede lovorvišnja (P. laurocerasus) i tisa (T. baccata) gde su preko 90\% otrovanih bila deca. Prema podacima toksikološkog centra u Americi, od 50 hiljada telefonskih poziva koje ovaj centar godišnje primi, $8 \%$ poziva je vezano za trovanja 
dece biljkama (Diaz, 2016). Kod dece do trovanja najčešće dolazi nepažnjom, kada deca probaju neki otrovni deo biljke, kod adolescenata prilikom isprobavanja nekih halucinogenih svojstava biljke, a kod odraslih do trovanja najčešće dolazi zamenom otrovnih i jestivih biljaka (Diaz, 2016). Fančovičová \& Prokop (2011) istraživali su koliko deca uzrasta 10-17 godina, raspoznaju otrovne plodove od jestivih plodova biljaka. Istraživanje je pokazalo da mlađa deca ne poznaju dovoljno dobro koji plodovi su otrovni a koji jestvi. Međutim, istraživanje je takođe pokazalo i to da sposobnost raspoznavanja otrovnih biljaka od jestivih, se ne povećava sa brojem godina deteta, te da je u tom smislu, potrebno obrazovati decu.

U Srbiji se takođe beleže trovanja biljkama. Prema podacima Centra za kontrolu trovanja Vojno-medicinske akademije u Beogradu, 2011. godine je zabeleženo tri slučaja trovanja plodom biljke Datura stramonium L. od čega je jedan bolesnik imao teško trovanje sa izraženom hepatotoksičnošću. U toku 2012.godine zabeleženo je trovanje plodovima biljaka kod 15 osoba. Kod 11 osoba radilo se o trovanju semenom biljke D. stramonium, a 4 osobe su intoksikovane plodom Atropa belladonna Linn.(www.vma.mod.gov.rs).

Vrsta T. orientalis sadrži otrovne sastojke tujon i tujaplicin u etarskom ulju, smonim žlezdicama koje se nalaze na vrhu grančice. Količina tujona u etarskom ulju može biti i do 60\%. Otrovni su i svi dekorativni kultivari ove vrste. Trovanja uzrokovana sirovim biljnim materijalom su ipak retka (Ivanić i sar. 1996). Na istraživanoj površini grane ove vrste polaze od zemlje i dostupne su deci, koja iz znatiželje i nepažnje mogu probati delove grančice.

Vrsta L. anagiroides spada u veoma toksične biljke čiji su svi delovi otrovni, sadrži otrovan sastojak citizin. Česta trovanja su zabeležena kod dece koja beru otrovne cvetove koji podsećaju na cvet bagrema koji nije otrovan, i isisavaju nektar. Semenke su takođe, otrovne. Do ozbiljnih trovanja dolazi ako dete pojede dve semenke, a letalna doza za odrasle je 15-20 semenki (Ivanić i sar. 1996, Kupper \& Reichert, 2009). Zabeleženi su slučajevi trovanja cvetovima ove vrste u Sloveniji (Vončina et al. 2015). Premerom elemenata rasta vrste L. anagyroides na istraživanoj površini utvrđeno je da je prosečna visina debla 1,5 m. Prve grane kreću sa visine od 1,5 m, što ih čini dostupnim starijoj deci u vrtiću, pa je neophodna opreznost.

Sa 38 stabala vrsta $R$. pseudoacacia je najbrojnija otrovna drvenasta vrsta na istraživanoj površini. Svi delovi biljke, osim cveta su otrovni (kora, seme, list). Otrovnost potiče od toksalbumina robina, koji se u najvećem procentu nalazi u kori koja je i najotrovnija. Zabeleženi su slučajevi trovanja dece korom (Tucakov, 1971; Ivanić i sar. 1996). Na istraživanoj površini deci su dostupni kora i mahune koje otpadnu.

Vrsta $R$. typhina spada u uslovno toksične biljke, štetni mogu biti cvast, list i kora zbog visokog sadržaja tanina (Ivanić i sar. 1996). Obzirom da se kod uočenog primerka prve grane nalaze na $1,9 \mathrm{~m}$, deci je dostupna jedino kora. 
Prema Frohne, Pfänder (1997) vrste iz roda Quercus zbog velikog sadržaja tanina mogu se smatrati otrovnim. Ipak trovanja dece plodovima ovih vrsta su veoma retka, a u slučaju da se dese izazivaju blaže stepene trovanja. Plodovi mogu biti i jestivi ako se na odgovarajući način konzumiraju.

Kod vrste A. hyppocastanum otrovne materije saponini (saponin escin) nalaze se u semenu, te se iz tog razloga seme ove vrste može smatrati otrovnim u sirovom stanju. Frohne, Pfänder (1997) navode da su zabeleženi slučajevi trovanja dece semenom ove vrste. Trovanja u zavisnosti od slučaja, mogu se kretati od blažih do teških (Frohne, Pfänder, 1997). Pečeno seme je jestivo. S obzirom na činjenicu da je seme tvrdo i krupno mala je verovatnoća da će privući decu da probaju isto. Na istraživanoj površini semena ove vrste kada opadnu su dostupna deci.

Kod vrste T. baccata, u svim delovima biljke, osim omotača semena arilusa koji je jestiv, nalazi se otrovni alkaloid taksin kao i cijanogeni glikozid. Arilus, unutar koga se nalazi otrovno seme, je crvene boje i on kao takav najviše privlači decu. Trovanja četinama i semenom T. baccata mogu biti veoma teška, sa fatalnim ishodom (Grlić, 1984; Frohne, Pfänder 1997; Ivanić i sar. 1996). U dvorištu vrtića zastupljena su dva žbuna većih dimenzija ove vrste, deca mogu dohvatiti grane od oba žbuna. U Češkoj, prema istraživanjima Vichova \& Jahodar (2003) trovanje vrstom T.baccata se nalazi na trećem mestu posmatrajući po broju hospitalizovane dece.

Svi delovi vrste $P$. laurocerasus su otrovni osim mesnatog dela ploda koji je neškodljiv. U svežem lišću i semenkama prisutni su cijanogeni glikozid prunazin i glikozid amigdalin. Trovanja su retka zbog oporog i gorkog ukusa ploda (Grlić, 1984; Ivanić i sar. 1996). Na istraživanoj površini prisutno je dva žbuna ove vrste.

Vrsta L. vulgare poseduje crne, sjajne plodove koji su otrovni i gorki. Smatra se da otrovnost potiče od saponozida, a prisutni su i glikozidi i gorka supstanca seko-iridoid. Ova vrsta spada u vrlo toksične biljke, ali su trovanja retka (Ivanić i sar. 1996). Isti autori navode da ova vrsta ne formira plod ako se redovno orezuje. Na istraživanoj površini ova vrste se nalazi kao „živa ograda“ $u$ jednom manjem delu.

Vrsta $H$. helix sadrži saponin hederin koji ima otrovno dejstvo. Trovanja plodovima $H$. helix kod dece nisu česta jer su plodovi gorkog ukusa. List vrste $H$. helix može izazvati kontaktne alergije koje se manifestuju u vidu kontaktnog dermatitisa (Grlić, 1984; Frohne, Pfänder 1997; Ivanić i sar. 1996). U dvorištu vrtića postoji manja površina pod ovom povijušom. Proučavanjima ove vrste sa različitih aspekata bavili su se Stavretović i sar. (2005), Stavretović (2007).

Povijuša C. vitalba sadrži otrovnu supstancu protoanemonin. U nekim zemljama (Francuska, Italija) i pored činjenice da spada u otrovne, ova vrsta se koristi za ishranu (mladi izdanci na poseban način pripremljeni). Vrsta izaziva kontakt alergije poput plikova i rana na koži (Kojić i Janjić, 1991). 


\section{ZAKLJUČAK}

Na istraživanoj zelenoj površini vrtića „Suncokreti“ u naselju Višnjička banja u Beogradu konstatovano je ukupno 26 drvenastih vrsta sa 227 stabala, pet vrsta žbunastog habitusa, kao i dve povijuše. Uočeno je prisustvo 11 otrovnih vrsta, od čega je 6 drvenastih (T. orientalis, L. anagyroides, R.pseudoacacia, R. typhina, Q.virgilliana, A. hyppocastanum), 3 žbunaste vrste (T. baccata, P. laurocerasus, L. vulgare) i dve otrovne povijuše ( $H$. helix, $C$. vitalba). Takođe je uočeno prisustvo i 9 vrsta sa alergenim karakteristikama polena, a jedna vrsta poseduje invazivne karakteristike. Vrsta R. pseudoacacia je najbrojnija otrovna drvenasta vrsta na istraživanoj površini (38 stabala).

Po najvećem stepenu otrovnosti izdvajaju se vrste T. orientalis, L. anagyroides $i$ T. baccata koje, u slučaju dospeća u ljudski organizam, izazivaju teška trovanja koja mogu imati fatalan ishod. Vrste R. typhina, Q. virgilliana, C. vitalba i P. laurocerasus spadaju u uslovno toksične biljke, izazivaju blaža trovanja, i one imaju najmanji stepen otrovnosti.

Konstatovano je da su sve otrovne vrste zabeležene na istraživanoj površini, odnosno njihovi otrovni delovi u većoj ili manjoj meri dostupni deci, te je u skladu s tim potrebna opreznost vaspitača, kao i obrazovanje u smislu prepoznavanja ovih vrsta i reagovanja u slučaju incidenta.

Potrebno je istaći i da pojedine vrste koje su u ovom radu navedene kao otrovne mogu imati i lekovita svojstva, a pojedine i jestive delove. Da li je određena biljka otrov ili lek, zavisi od načina upotrebe, količine otrovnih sastojaka u biljci, kao i od toga koji deo biljke i u kom delu vegetacionog perioda se koristi. Zadatak rada je bio skrenuti pažnju na stanje i dati preporuku za buduće planove uređenja ovog tipa zelenih površina.

Sadnju otrovnih drvenastih i žbunastih vrsta u parkovima i ostalim zelenim površinama nije neophodno izbegavati, ali je svakako poželjno ne gajiti ih na mestima poput školskih i predškolskih dvorišta gde bi bile uvek dostupne deci. Boljim poznavanjem otrovnih biljaka, uz odgovarajuće mere opreza može se minimalizovati broj trovanja. Takođe, prilikom planiranja i projektovanja, osim otrovnih, poželjno bi bilo ne predviđati ni invazivne ni alergene drvenaste vrste na zelenim površinama obdaništa.

Zahvalnica: Ovaj rad je realizovan u okviru projekta „Istraživanje klimatskih promena i njihovog uticaja na životnu sredinu - praćenje uticaja, adaptacija i ublažavanje“ (43007) finansiranog od strane Ministarstva prosvete, nauke i tehnološkog razvoja Republike Srbije u okviru integrisanih interdisciplinarnih istraživanja za period 2011-2016. 


\section{LITERATURA}

Banković, S, Pantić, D.:Dendrometrija. Šumarski fakultet Beograd, Srbija, 2006.

Diaz, J. H.: Poisoning by Herbs and Plants: Rapid Toxidromic Classification and Diagno sis. Wilderness \& Environmental Medicine, Department of Environmental and Oc cupational Health Sciences, School of Public Health; Department of Anesthesiology/ Critical Care, School of Medicine, Louisiana State University Health Sciences Center (LSUHSC) in New Orleans, New Orleans, LA., 27(1):136-152, 2016.

Frohne, V. D., Pfänder, H. J.: Giftpflanzen: Eine Handbuch für Apotheker, Ärzte, Toxikologen und Biologen, Kiel, 1997.

Fančovičová, J., Prokop, P.: Children's ability to recognise toxic and non-toxic fruits. Eurasia Journal of Mathematics, Science \& Technology Education, 7.2: 115-120, 2011.

Grlić, LJ. : 99 jestivih i otrovnih boba, Prosveta, Zagreb, 1984.

Ivanić, R., Savin, K., Lemajić, Lj.: Otrovno drveće i grmlje naših zelenih površina, Plato, Beograd, 1996.

Kojić, M., Janjić, V.: Otrovne biljke, Naučna knjiga. Beograd, 1991.

Kupper, J., Reichert, C.: Intoxications with plants. Therapeutische Umschau. Revue therapeu tique, 66.5: 343-348, 2009.

Lawrence, R. A.: Poisonous plants: when they are a threat to children, Pediatrics in Review, Univer sity of Rochester School of Medicine, Rochester, NY, USA, 18(5):162-168, 1997.

Ocokoljić, M., Ninić-Todorović, J.: Priručnik iz dekorativne dendrologije, Šumarski fakultet, Beograd, 2003.

Cvjetićanin, R, Petrović, M.: Praktikum iz dendrologije, Šumarski fakultet 2010.

Stavretović, N., Radošević, G., Ilić, B.: "Morfološke i anatomske osobine bršljana", U R.

Pantović i sar. (Ed.), Zbornik radova naučno-stručnog skupa o prirodnim vrednostima i zaštiti životne sredine, "Ekološka istina 2005", 2005, 390-393.

Tucakov, J.: Lečenje biljem (fitoterapija), Kultura, Beograd, 1971.

Šilić, Č.: Atlas drveća i grmlja, Sarajevo, Beograd, 1990.

Vićentić, S., Petrović, J., Stavretović, N.,: Prisustvo alergenih drvenastih vrsta u obdaništima i školama u naselju Borča, Beograd, Republika Srbija, U B. Dikić i sar. (Ed.), Zbornik radova VI Međunarodnog kongresa „Ekologija, zdravlje, rad, sport“, Banja Luka, 2015.

Vichova, P., Jahodar, L.: Plant poisonings in children in the Czech Republic, 1996-2001. Hu man \& experimental toxicology, 2003, 22.9: 467-472.

Vončina, M., Baričevič, D., Brvar, M.: Adverse effects and intoxications related to medicinal/ harmful plants. Acta agriculturae Slovenica, 103.2: 263-270, 2015.

Vukićević, E.: Dekorativna dendrologija, Naučna knjiga, Beograd, 1996.

Anonimni autor: Godišnjak centra za kontrolu trovanja 2011, http://www.vma.mod.gov.rs/sr-lat/ specijalnosti/centri/nacionalni-centar-za-kontrolu-trovanja/godisnjak-NCKT 


\section{Summary}

On the green areas preschools and schools can find a variety of woody species, among which there are invasive, allergenic and toxic. Toxic woody species differ in their degree of toxicity. In the case of maturity in the human body of a toxic plants can cause minor, some major disruptions, and some can even lead to death. Toxic woody and shrub species are not desirable in the green areas of school and especially pre-school institutions. Despite numerous poisonous woody and shrub species are found in them, which can pose a serious threat to the health of children. The aim was to determine the presence of poisonous trees and shrub species on the surface of the green kindergarten "Sunflowers" in the suburb Višnjička banja in Belgrade.

The studies were conducted on the green area kindergarten "Sunflowers" in the suburb Višnjička banja in Belgrade. Determination of trees and shrub species was determined according Vukicevic (1996), and Ocokoljić Ninić-Todorović (2003), Šilic (1990), Cvjetićanin and Perovic (2010). Toxic woody species are separated according Grlić (1984), Frohne, Pfänder (1997), Ivanić et al., (1996). The degree of toxicity was determined according to the type of Ivanić et al., (1996) and Frohne, Pfänder (1997).

In relation to whether cause mild, severe or very severe fatal poisoning in case of entry into the body, ascertained poisonous species are divided into conditionally toxic, toxic, very toxic, and types that cause very serious, fatal poisoning. Depending on the size of wood, flowers, fruits and seeds can be more or less accessible to children, and for that reason the diameter of the elements carried by tree growth Banković and Pantić (2006).

In the courtyard of the kindergarten "Sunflowers" was recorded 26 tree species with 227 trees. There are also five species of bush habit, as well as two climbing plants. Of the total of 26 woody species 6 is one of those whose individual parts or the whole plant-toxic (Thuja orientalis, Laburnum anagyroides, Robinia pseudoacacia, Rhus typhina, virgilliana Quercus, Aesculus hippocastanum). Of the five species of woody bushy habit, 3 species belong to the poisonous (Taxus baccata, Prunus laurocerasus, Ligustrum vulgare). Differences were two poisonous climbing plants (Hedera helix, Clematis vitalba). In total there are 11 toxic species.

It was noted that all poisonous species recorded in the studied area, or their toxic components in more or less accessible to children, and it is accordingly necessary caution educators, and education in terms of recognition of these species and to react in case of an incident. Toxic planting trees and shrub species in parks and other green areas is not necessary to avoid, but it is certainly not desirable to cultivate them in places such as school and pre-school yard where they were always available to children. Better knowledge of poisonous plants, with proper precautions can minimize the number of poisoning. Also, during the planning and design, except toxic, it would be desirable not to predict invasive and allergenic tree species in green areas nursery.

Keywords: poisonous species, kindergartens landscaping, horticulture, Belgrade 